\title{
$\&$ Global neurosurgery and our social responsibility
}

\author{
James T. Rutka, MD, PhD \\ Editor-in-Chief, Journal of Neurosurgery Publishing Group, Charlottesville, Virginia
}

$I^{2}$ $\mathrm{N}$ this issue of the Journal, I am pleased to highlight and promote the publication of 9 new articles on the topic of global neurosurgery. ${ }^{4-10,12,13}$ Many of the articles in this issue are derived from the efforts of authors from the Global Neurosurgery Initiative and the Program in Global Surgery and Social Change at Harvard and their numerous collaborators. These articles follow on the heels of a recent issue in Neurosurgical Focus (Volume 45: Issue 4,October, 2018) that was entirely devoted to reducing inequities in global neurosurgery delivery. In that issue, the contributions from leaders in the field encompassed topics such as existing international outreach programs, the identification of global neurosurgery needs and solutions, the use of big data to promote global neurosurgery efforts, and the key role that neurosurgeons can play as advocates for health policy creation and prevention of neurosurgical disease states. ${ }^{2}$

The deficiencies identified in the delivery of basic neurosurgical care worldwide are staggering, as are the numbers of individuals affected. The statistics you will read in these articles are both compelling and sobering: The estimate of gross domestic product losses from patients suffering from neurosurgical diseases will exceed $\$ 4.4$ trillion over the next 15 years; there are approximately 49,940 neurosurgeons worldwide, but it is calculated that more than 23,000 additional neurosurgeons are needed to meet the current patient case load particularly in Africa and Southeast Asia; the incidence of hydrocephalus in infants and children is higher in low- and middle-income countries (LMICs) than in high-income countries; the global incidence of traumatic brain injury is unimaginable, with 69 million individuals affected each year; and the global burden of epilepsy is enormous, with an estimated 1.4 million individuals worldwide who would benefit from epilepsy surgery each year, especially in Africa and Latin America.

The term "global neurosurgery" has only recently been introduced into the vernacular of academic neurosurgery, and its acceptance as a term is indicated by the growing number of peer-reviewed publications in the field. Many institutions in North America have developed or are developing initiatives in global neurosurgery. There are numerous neurosurgical organizations with a mandate to support global neurosurgery including the Foundation for International Education in Neurological Surgery (FIENS), ${ }^{3}$ the World Federation of Neurosurgical Societies (WFNS), the World Health Organization (WHO), the American Association of Neurological Surgeons (AANS), the Congress of Neurological Surgeons (CNS), the European Association of Neurological Surgeons (EANS), the Asian Australasian Society of Neurological Surgeons (AASNS), and the International Society of Pediatric Neurosurgery (ISPN) to name just a few.

I had the pleasure of attending a recent conference at Weill Cornell Medical College in New York City, on January 19, 2019, entitled "Global Neurosurgery 2019: A Practical Symposium." Participants from around the world gathered to discuss their efforts and models in countries such as Haiti, Tanzania, Vietnam, Cambodia, and Bolivia. Specific challenges, solutions and successful projects, key failures, and lessons learned were all discussed. At the symposium, I had the great privilege of discussing our global neurosurgery effort over the past 5 years in Ukraine ${ }^{11}$ (Fig. 1). Conferences such as these will do much to establish a strong network of individuals, institutions, and neurosurgical organizations that are devoted to making change. There are numerous sustainable goals that we should strive to achieve in neurosurgery worldwide, including a 50\% reduction in mortality in head trauma, universal healthcare coverage, increased health financing, and improving neurosurgical capacity through partnerships. ${ }^{1}$

In North America, we are extremely fortunate to practice neurosurgery with all the innovations and technologies that enable us to achieve the best outcomes for patients with the most difficult and challenging neurosurgical conditions. Unfortunately, the same cannot be said of our colleagues whose neurosurgical practices reside in LMICs. 


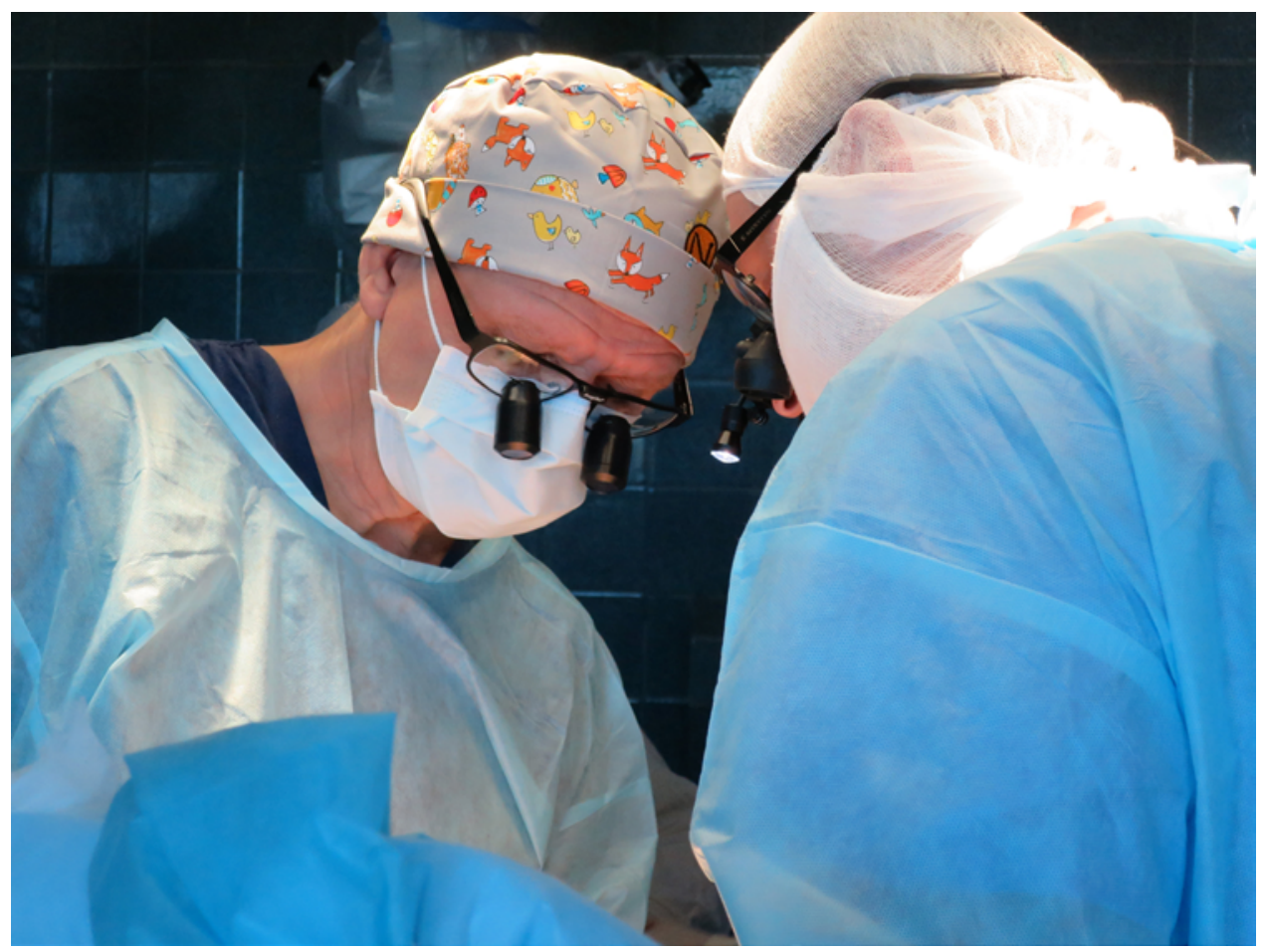

FIG. 1. Neurosurgery outreach to Ukraine. The editor-in-chief (left) is shown assisting Lviv City Children's Hospital neurosurgeon, Taras Mykytyn, in the removal of an intracranial brain tumor in a child, in Lviv, Ukraine, June 2017. Photo credit: Dr. Myroslava Romach, University of Toronto. Figure is available in color online only.

Accordingly, I strongly believe it is our social responsibility to provide education and support to our neurosurgical colleagues around the globe who struggle to treat the population of patients who seek their attention and care. I, for one, have found that my efforts in global neurosurgery are among the most gratifying and fulfilling of all I have experienced throughout my career. Thanks to the efforts now of so many neurosurgeons in institutions and organizations around the world, our opportunities to become involved in global neurosurgery projects are numerous, diverse, and impactful. As Editor-in-Chief of the Journal of Neurosurgery, I will be pleased to consider many future contributions on the topic of global neurosurgery in the pages of this journal.

https://thejns.org/doi/abs/10.3171/2019.1.JNS19189

\section{References}

1. Barthélemy EJ, Park KB, Johnson W: Neurosurgery and sustainable development goals. World Neurosurgery 120:143-152, 2018

2. Branch CL Jr, Boop F, Haglund MM, Dempsey RJ: Introduction. Neurosurgical opportunities in global health inequities. Neurosurgical Focus 45(4):E1, 2018

3. Dempsey RJ: Editorial. Global neurosurgery: the role of the individual neurosurgeon, the Foundation for International Education in Neurological Surgery, and "service through education" to assess worldwide need. Neurosurgical Focus 45(4):E19, 2018

4. Dewan MC, Rattani A, Baticulon RE, Faruque S, Johnson WD, Dempsey RJ, et al: Operative and consultative proportions of neurosurgical disease worldwide: estimation from the surgeon perspective. J Neurosurg [epub ahead of print May 11, 2018; DOI: 10.3171/2017.10.JNS17347]

5. Dewan MC, Rattani A, Fieggen G, Arraez MA, Servadei F, Boop FA, et al: Global neurosurgery: the current capacity and deficit in the provision of essential neurosurgical care. Executive Summary of the Global Neurosurgery Initiative at the Program in Global Surgery and Social Change. J Neurosurg [epub ahead of print April 27, 2018; DOI: 10.3171/2017.11.JNS171500]

6. Dewan MC, Rattani A, Gupta S, Baticulon RE, Hung YC, Punchak M, et al: Estimating the global incidence of traumatic brain injury. $\mathbf{J}$ Neurosurg [epub ahead of print April 27, 2018; DOI: 10.3171/2017.10.JNS17352]

7. Dewan MC, Rattani A, Mekary R, Glancz LJ, Yunusa I, Baticulon RE, et al: Global hydrocephalus epidemiology and incidence: systematic review and meta-analysis. J Neurosurg [epub ahead of print April 27, 2018; DOI: 10.3171/2017.10. JNS17439]

8. Fallah PN, Bernstein M: Barriers to participation in global surgery academic collaborations, and possible solutions: a qualitative study. J Neurosurg [epub ahead of print April 6, 2018; DOI: 10.3171/2017.10.JNS17435]

9. Mukhopadhyay S, Punchak M, Rattani A, Hung YC, Dahm J, Faruque S, et al: The global neurosurgical workforce: a mixed-methods assessment of density and growth. $\mathbf{J}$ Neurosurg [epub ahead of print January 4, 2019; DOI: 10.3171/2018.10.JNS171723]

10. Robertson FC, Lepard JR, Mekary RA, Davis MC, Yunusa I, Gormley WB, et al: Epidemiology of central nervous system infectious diseases: a meta-analysis and systematic review with implications for neurosurgeons worldwide. J Neurosurg [epub ahead of print June 15, 2018; DOI: 10.3171/2017.10.JNS17359]

11. Romach MK, Rutka JT: Building healthcare capacity in pe- 
diatric neurosurgery and psychiatry in a post-Soviet system: Ukraine. World Neurosurgery 111:166-174, 2017

12. Rudolfson N, Dewan MC, Park KB, Shrime MG, Meara JG, Alkire BC: The economic consequences of neurosurgical disease in low- and middle-income countries. J Neurosurg [epub ahead of print May 18, 2018; DOI: 10.3171/2017.12. JNS17281]

13. Vaughan KA, Lopez Ramos C, Buch VP, Mekary RA, Amundson JR, Shah M, et al: An estimation of global volume of surgically treatable epilepsy based on a systematic review and meta-analysis of epilepsy. J Neurosurg [epub ahead of print September 14, 2018; DOI: 10.3171/2018.3.JNS171722]

\section{Disclosures}

The author reports no conflict of intererst.

\section{Correspondence}

James T. Rutka: james.rutka@sickkids.ca.

INCLUDE WHEN CITING

DOI: 10.3171/2019.1.JNS19189. 